\title{
Assessing Lecturers' Performance using Fuzzy Logic
}

\author{
Umar Farouk lbn \\ Abdulrahman \\ Christ Apostolic University \\ College \\ Kumasi-Ghana
}

\author{
Suleman Shamsu-Deen \\ Sunyani Technical University \\ Sunyani-Ghana
}

\author{
Emmanuel Kwame \\ Abaidoo \\ Christ Apostolic University \\ College \\ Kumasi-Ghana
}

\begin{abstract}
Assessing lecturers is a routine work conducted at various universities to ascertain the academic performance of the lecturers. In literature, various methods and variables are being employed to do the evaluation. The objective of this research was to employ fuzzy logic in assessment of lecturers as against the traditional statistical methods. Four input variables, namely lecturer delivery, punctuality, interaction with students and assignment were used which produces a single output- Result, with its linguistic terms as Excellent, Fair, Good or Poor. The result shows that Fuzzy logic can be a simpler way of evaluating lecturers.
\end{abstract}

\section{Keywords}

Lecturers Assessment, Fuzzy logic, Fuzzification, Defuzzification

\section{INTRODUCTION}

All over the world universities are considered the highest academic learning institutions. At the universities both undergraduate and post-graduate courses are taught. However for some universities only undergraduate or postgraduates courses are taught.

Lecturers at the universities are expected to teach certain number of courses and also demonstrate some level of proficiency in the courses they teach. To ensure quality of education, universities employ assessment criteria to asses each lecturer's performance over a period of time to ascertain the level of delivery and proficiency of the said lecturer.

According to [2], the main purpose of evaluation is to provide information and feedback to academic staff on their teaching performance which in turn should enable them do some selfreflection and eventually take some necessary action to enhance their teaching performance in their function.

Over the years, various assessment methods have been employed to assess lecturers' academic performance. Most notable among them are the statistical tools. Fuzzy logic can however be a better alternative.

\section{RELATED WORK}

Evaluation of lecturers' performance has been dealt with for some time now. Various criteria and varying parameters have been used by different authors.[3] Used 34 items among which were punctuality, teaching for the whole period, encourage students to answer question etc. The mean and standard deviation of the items were found.[2] Used 4 variables namely planning and preparation, delivery techniques, assessment, student-lecturer relation. All this were statistical.

Fuzzy logic is an extension of the classical set theory. It was proposed by Prof. Lofti Zadeh in the year 1965. It is mostly used to deal with imprecision and vagueness of human subjective judgment and represent information from zero to one [9].

Fuzzy logic has received attention in several domains including its application in lecturers' assessments.[6] used fuzzy logic in teacher performance evaluation. Fifteen items were used in the evaluation criteria. In another research, [4] applied fuzzy logic in employee performance appraisal system. [5] conducted students' performance evaluation using fuzzy logic reasoning. Five attributes were used in the evaluation criteria.[9] Applied fuzzy logic to credit scoring in Ghana to determine the credit worthiness of applicants.

\section{METHODOLOGY}

Fuzzy logic uses input and output variables in the construction of inference rules. Therefore the first process was to identify input, output variables and their linguistic terms

There are not generally or universally agreed inputs and outputs for lecturers' assessment. Therefore the input and output variables used for this research were obtained from the Quality control section of the Christ Apostolic University College's (www.cauc.edu.gh) for the year, 2014. They are

Lecturer Delivery,-Ability of a lecturer to deliver a course

Interaction with Students: Lecturer's engagement with students to motivate them

Punctuality: The number of times a lecturer goes to the lecturer room

Assignment: Lecturer offers and marks assignment given to students

The input and output parameters were placed in the fuzzy threshold as shown in tables 1 and 2 respectively

Table 1 Input Variables And Their Thresholds

\begin{tabular}{|l|l|r|}
\hline INPUT NAME & LINGUISTIC & \multicolumn{1}{|l|}{ RANGE } \\
\hline Lecture Delivery & Excellent & $.70-1.00$ \\
\hline & Fair & $.55-.70$ \\
\hline & Average & $.40-. .55$ \\
\hline Interaction With Students & Excellent & $.70-1.00$ \\
\hline & Fair & $.55-.70$ \\
\hline & Average & $.40-. .55$ \\
\hline
\end{tabular}




\begin{tabular}{|l|l|r|}
\hline & Poor & $0-.40$ \\
\hline Punctuality & Excellent & $.70-1.00$ \\
\hline & Fair & $.55-.70$ \\
\hline & Average & $.40-. .55$ \\
\hline Assignment & Poor & $0-.40$ \\
\hline & Excellent & $.70-1.00$ \\
\hline & Fair & $.55-.70$ \\
\hline & Average & $.40-. .55$ \\
\hline & Poor & $0-.40$ \\
\hline
\end{tabular}

Tabel 2 Output Variable A

\begin{tabular}{|l|l|}
\hline Result & RANGE \\
\hline Excellent & $80.1-100$ \\
\hline Fair & $60.1-80$ \\
\hline Average & $40.1-60$ \\
\hline Poor & $0-.40$ \\
\hline
\end{tabular}

Sample input and output were plotted graphically using Matlab 7.0 as shown in Figures 1 and 2

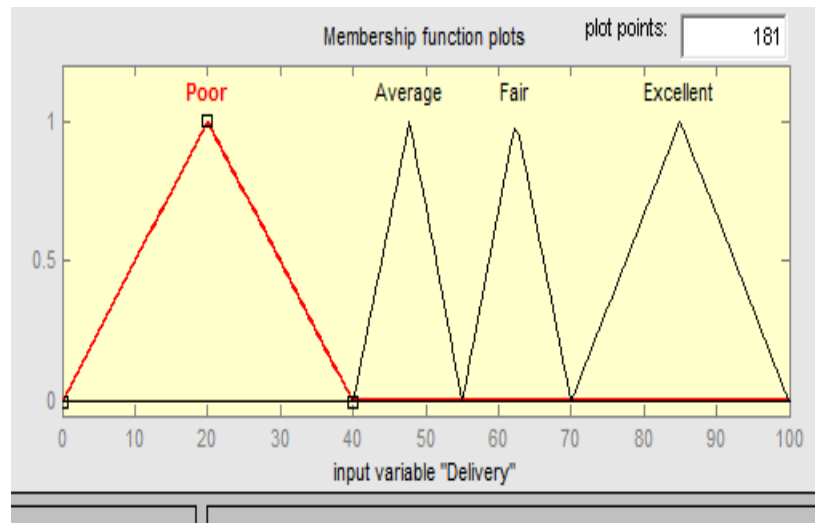

Fig. 1. Input variable Lecture Deliver

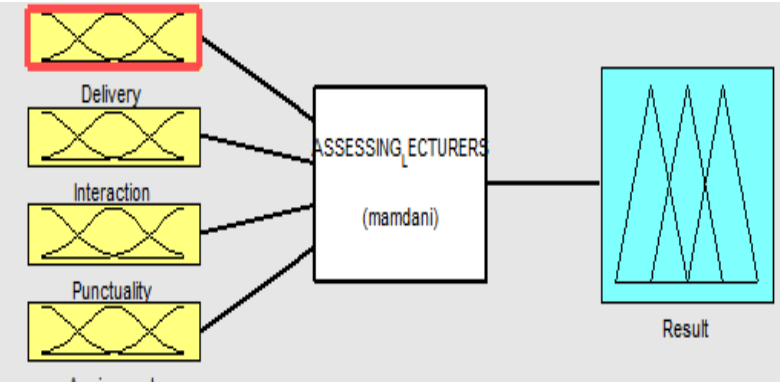

Fig 2. Input and output Variables

A fuzzy decision matrix was constructed using the input variables and an output to indicate the result. Fuzzy rules were obtained to form the rule-base for the fuzzy inference engine. Further, the min-operator was employed in the rule construction and the centroid method to defuzzify the result

\section{Sample rules are}

1. If Delivery(Excellent) and Interaction(Average) and Punctuality(Average) and Assignment (Average) then Result(Fair)

2. If Delivery(poor) and Interaction(Average) and Punctuality(Excellent) and Assignment (Average) then Result(Average)

3. If Delivery(poor) and Interaction(poor) and Punctuality(poor) and Assignment (poor) then Result(Poor)

4. If Delivery(Excellent) and Interaction(Excellent) and Punctuality Excellent) and Assignment (p Excellent) then Result(Excellent)

5. If Delivery(poor) and Interaction(Excellent) and Punctuality(Average) and Assignment (Fair) then Result(Average)

\section{IMPEMENTATION}

Implementation of fuzzy logic systems normally goes through four stages to which this research was no exception. These are Fuzzification, Data-store, inference and Defuzzification stages respectively.

The process started by capturing the four input parameters into the fuzzy system. At the Fuzzification stage all the crisp values entered were converted to fuzzy values which was sent to the Data Store. The Data Store has a link with the inference engine which processes all the rules in the system. The final stage is to convert back the fuzzy values to crisp values which is termed as Defuzzification. The Centre-of-Gravity (CoG) Defuzzification method was used. This is because CoG Defuzzification method is simple and requires less computation effort compared to MOM, MAX, HD and CoS [8]. 


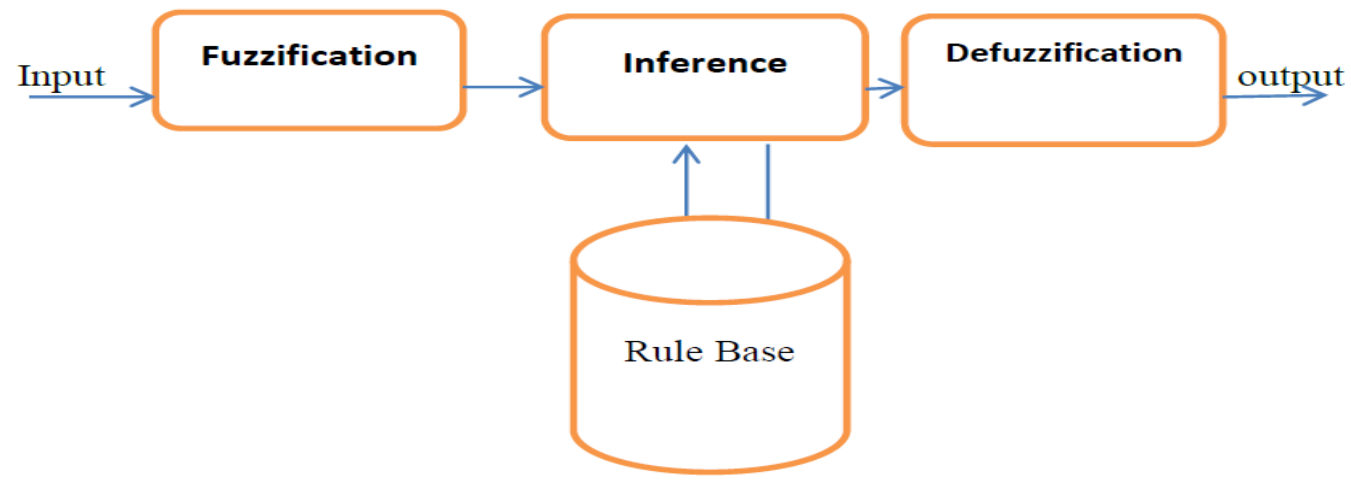

Fig 3. Fuzzy Inference System

Fig. 4 and 5 below shows examples of simulated results

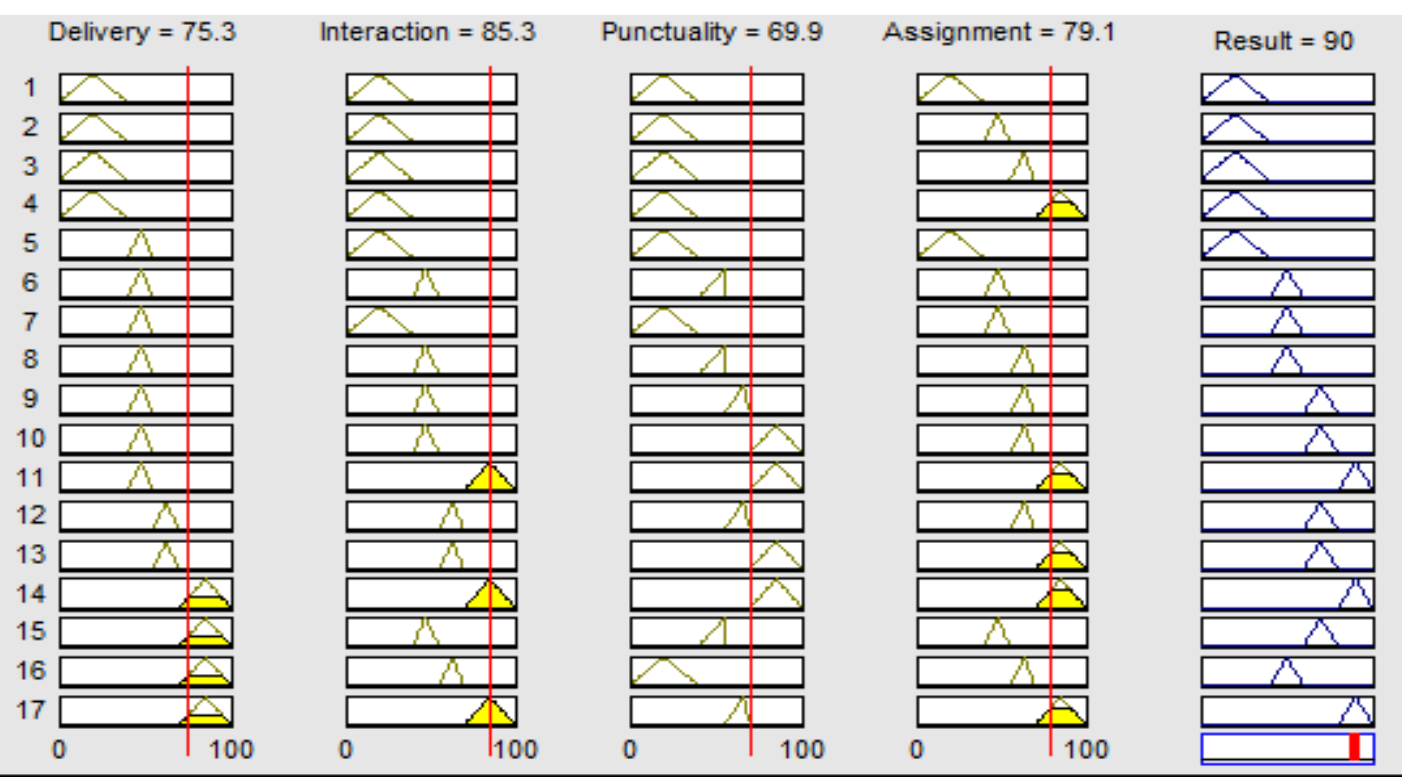

Fig. 4. Sample Simulated Result- Excellent

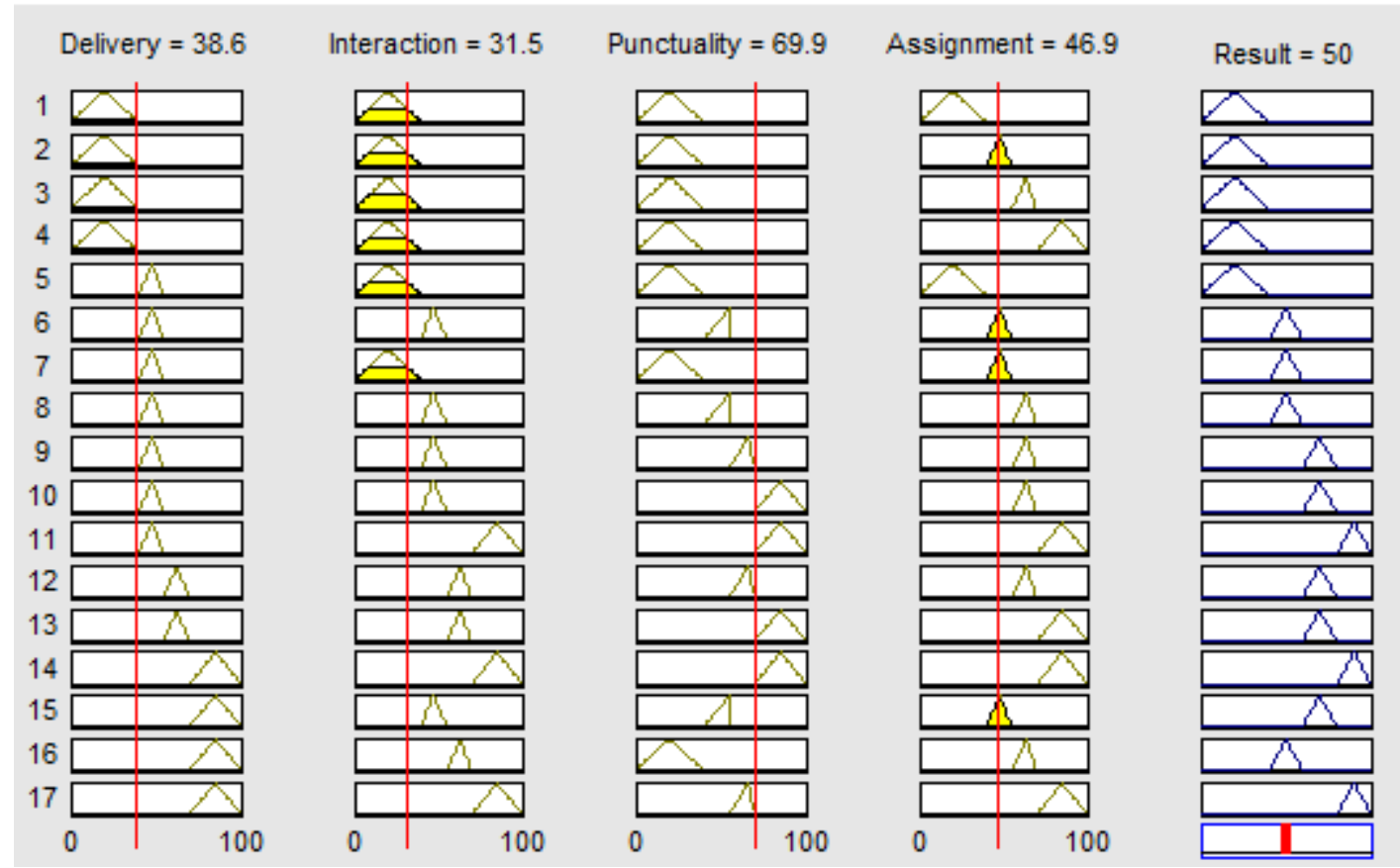

Fig. 5. Sample Simulated Result-Good 
Table 3. Sample Simulated Results

\begin{tabular}{|l|l|l|l|l|l|}
\hline NO & DELIVERY & INTERACTION & PUNCTUALITY & ASSIGNMENT & RESULT \\
\hline 1 & 28 & 17.7 & 25 & 31.5 & 20 \\
\hline 2 & 68.9 & 39.2 & 25 & 36.2 & 50 \\
\hline 3 & 49.2 & 53.1 & 55.3 & 63.8 & 52.2 \\
\hline 4 & 81.1 & 73.1 & 72 & 76.2 & 90 \\
\hline 5 & 19.9 & 25.4 & 17.4 & 28.5 & 20 \\
\hline 6 & 68.4 & 62.2. & 71.1 & 71.6 & 70 \\
\hline 7 & 30 & 39.8 & 38 & 39.8 & 20 \\
\hline 8 & 80.7 & 54 & 48.5 & 50.9 & 60 \\
\hline 9 & 69.6 & 83 & 82.9 & 82.4 & 80 \\
\hline 10 & 50 & 41 & 75.6 & 45.4 & 50 \\
\hline
\end{tabular}

Table 3 shows sample simulated results.

We can then infer from the output variable of table 2, that, Results are

$$
\begin{aligned}
& 80.1>=\text { Results }>=100 \text { Excellent } \\
& 60.1>=\text { Results }>=80 \text { Fair } \\
& 40.1>=\text { Results }>=60 \text { Average } \\
& 0>=\text { Results }>=40 \text { Poor }
\end{aligned}
$$

\section{CONCLUSION}

In this research, we applied Fuzzy logic in the assessment of academic performance of lectures'. It was observed that, using the right input, output and their linguistic terms Fuzzy logic can offer a simple interpretable results

\section{ACKNOWLEDGMENTS}

Our special thanks goes to Prof. Clement Somuah, Dean School of Technology who also doubles as the Head of Quality Control Section of Christ Apostolic University

\section{REFERENCES}

[1] Fuzzy Logic", Stanford Encyclopedia ofPhilosophy,Stanford University. 2006-07-23,http:// plato. stanford. Edu / entries / logic-fuzzy (accessed 2016,May, 07)

[2] Samian, Y. and Norah, N. MD 2012 Students' perception on Good Lecturer Based on Lecturer Performance Assessment, Int. Conference on Teaching and Learning in Higher Education(2012).

[3] Jegede, P. and Adeyemo, E, Emily. 2015. Factor Analytic Study of Lecturers's Teaching Assessment
Scale in Obafemi Awolowo University, Nigeria, World Journal of Education, Vol 5, No3, 2015

[4] Shaout, A. and Yousif, M, Khalid, 2014, Employee Performance Appraisal System Using Fuzzy Logic, Int. Journal of computer Science and Information Technology, Vol 6, No 4, August, 2014

[5] Kharola, A., Kunwar, S. and Choudhury, B, G, 2015, Students Performance Evaluation; A Fuzzy Logic reasoning approach, PM World Journal, Vol IV, issue IX September 2015

[6] Fuzzy inference www2.cs.siu.edu/ rahimi/cs437/slides/lec05.ppt

[7] Cauc.edu.gh, The Christ Apostolic University College, Kumasi Ghana

[8] Duodu, Q. Joseph K. Panford and James B. HafronAcquah, Designing Algorithm for Malaria Diagnosis using Fuzzy Logic for Treatment (AMDFLT) in Ghana, International Journal of Computer Applications (0975 8887) Volume 91-No.17, April 2014

[9] Umar Farouk Ibn Abdulrahman, Joseph K. Panford, James B. Hayfron-Acquah, (2014), Fuzzy Logic Approach to credit Scoring, A case study of KwiqPlus Money Lending, International Journal of Computer Application, (0975-8887), Volume 94 - No.8, May 2014

[10] Chen, L-H., Chiou, T-W, (1999), A fuzzy credit ratingapproach for commercial loans; A Taiwan case. OmegaInternational Journal of Management Science 27(1999),407-419,1999. 